\section{Kidney \\ Blood Pressure Research}

\title{
Renal Functions and Prognosis Stratification in Chronic Heart Failure Patients and the Importance of Neutrophil Gelatinase-Associated Lipocalin
}

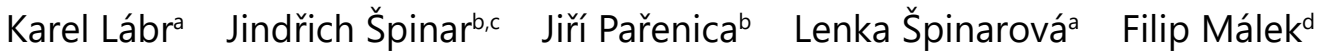 \\ Monika Špinarováa Ondřej Ludka ${ }^{b, c}$ Jiř́ Jarkovskýe Klára Benešováa \\ Monika Goldbergová-Pávkováf Růžena Lábrováb
}

aFirst Department of Internal Medicine - Cardioangiology, St. Anne's University Hospital, Faculty of Medicine, Masaryk University, Brno, 'Department of Internal Cardiology Medicine, Faculty Hospital Brno, Faculty of Medicine, Masaryk University, Brno, International Clinical Research Center, St. Anne's University Hospital, Brno, ${ }^{d}$ Department of Cardiology, Na Homolce Hospital, Prague, elnstitute of

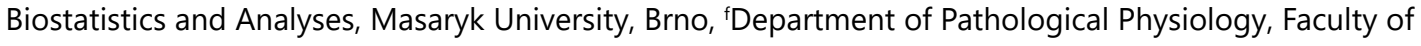
Medicine, Masaryk University, Brno, Czech Republic

\section{Key Words}

Chronic heart failure $\bullet$ Creatinine $\cdot$ Renal function $\bullet$ Neutrophil Gelatinase-associated Lipocalin - $\mathrm{N}$-terminal pro-brain natriuretic peptide

\begin{abstract}
Background/Aims: The rate of incidence and prevalence of acute kidney injury is increasing due to an increased number of patients with heart failure. Therefore it is very pertinent to early detect the level of renal injuries and to make necessary heart failure predictions. Thus the aim of this study is to determine renal functions and prognosis stratification in chronic heart failure patients and importance of Neutrophil Gelatinase-Associated Lipocalin (NGAL), an early diagnostic marker of acute kidney injury, as well as stratification of cardiovascular risk in heart failure patients. Methods: Data including age, gender, comorbidities and medical history of outpatients and hospitalized patients from Farmacology and NeuroHumoraL activation (FAR NHL) multicenter prospective registry comprising three Cardiological Centers in the Czech Republic were collected between 1st October 2014 and 30th November 2015. One-year follow-up data were collected in November 2016 in such a way that all patients had at least one-year data from the time of recruitment, but up to two years to the time of follow-up. One-year data were used for the whole set of patients while data up to 24 months were used with Kaplan-Meier's survival curves to analyse the patients' survival data. Blood samples were collected from the patients and basic parameters were evaluated in order to analyse Neutrophil gelatinase-associated lipocalin (NGAL) and plasma levels of $\mathrm{N}$-terminal




\section{Kidney Blood Pressure Research}

pro-brain natriuretic peptide (NT-ProBNP) using Lipocalin-2/NGAL Human ELISA kit (Bio Vendor, Czechia) and the Cobas E411 NT-proBNP Immunoassay kit (Roche Diagnostics, Indianapolis, IN, USA) respectively. Statistical analysis was further carried out to explain the level of significance of the evaluated parameters using Spearman Correlation, Mann Whitney or Kruskal-Wallis test and log-rank test. Results: Out of 547 patients from Farmacology and NeuroHumoraL activation (FAR NHL) multicenter prospective registry with available data on hospitalizations, mortality, biomarkers and one-year follow-up that were recorded, there were 439 males $(80.3 \%)$ with a median age of 66 years. At least one-month stable patients with left ventricle ejection fraction (LV EF) under $50 \%$ were recorded. The etiology of heart failure was ischemic heart disease in 54\%, dilated cardiomyopathy in $40 \%$ and others in $6 \% .69 \%$ patients were in New York Heart Association functional class II. There were 76 events (13.9\%; all-cause mortality, acute heart failure hospitalization, left ventricle assist device implantation and orthotopic heart transplant) in the first 365 days of follow-up. The area under the receiver operating characteristic curve was higher for NT-proBNP $(0.77)$ than the creatinine $(0.57)$, NGAL (0.55) or creatinine clearance (0.54). In multivariable analyses, NT-proBNP $(P=0.001)$ and NGAL $(P=0.004)$ were significant predictors of events. Subjects with NT-proBNP and NGAL above the cut off value (NT-proBNP 1,121 pg/ml, NGAL $80 \mathrm{ng} / \mathrm{ml}$ ) survived without any event in $55.7 \%$, subjects with NT-proBNP and NGAL under the cut off value survived without any event in $90.5 \%$, after two years $(P=0.001)$. Conclusion: The findings of the study showed that NGAL associated with NT-proBNP was a stronger predictor of the primary endpoint than NGAL or NT-proBNP alone. The level of NGAL was rising in hypertension, ischemia, anemia, hypoalbuminemia, diabetes or arrhythmias.

(C) 2018 The Author(s)

Published by S. Karger AG, Basel

\section{Introduction}

Heart failure with reduced ejection fraction (HFrEF) and Heart failure with mid-ranged ejection fraction (HFmrEF) are clinical syndromes characterized by typical symptoms (breathlessness, ankle swelling and fatigue) caused by structural or functional cardiac abnormality [1]. The prevalence of heart failure (HF) is approximately $1-2 \%$ of the adult population and it has risen by more than $10 \%$ among people older than 70 years [2].

The impaired renal function has been classified as a stronger predictor of mortality in chronic heart failure (CHF) than the reduced left ventricular ejection fraction (LVEF) or New York Heart Association (NYHA) functional class which similarly predicted mortality and natriuretic peptides [3]. With the increasing number of HF patients, the acute kidney injury (AKI) is increasing in incidence and prevalence [4]. It is very important to predict and detect renal injury.

Neutrophil gelatinase-associated lipocalin (NGAL, also known as lipocalin 2, siderocalin or $24 \mathrm{p} 3$ ) is a $25-\mathrm{kDa}$ epithelial monomeric protein that is covalently bound to gelatinase from human neutrophils and various epithelial cells. Its expression is up-regulated in AKI, but also during inflammation, renal and myocardial ischemia or infection [5-9].

The elevation of serum creatinine is the current gold standard in diagnostics of AKI. However, the concentration of creatine level changes within 2-3 days after the diagnosis of $\mathrm{AKI}$, as a result of this, serum creatinine is not a time marker of acute kidney injury, but NGAL rises within 2 hours. It makes NGAL the early diagnostic marker of AKI, and NGAL proved as one of the best markers for early diagnosis of AKI $[10,11]$.

NGAL predicts all the causes of mortality and death from cardiovascular issues in a patient with chronic heart failure [12] and acts as an overall marker for the level of severity of the cardiovascular disease [13].

Ideally, if natriuretic peptide which induces natriuresis would serve as a prognostic marker for ventricular stretch and possibly also for pulmonary congestion, it could be matched with a marker of renal injuries, such as NGAL and the combination could have been quite useful for risk stratification. 


\section{Kidney Blood Pressure Research}

Lábr et al.: NGAL and Prognosis in Chronic Heart Failure

We combined N-terminal pro-brain natriuretic peptide and NGAL in CHF to stratify prognosis of patients with heart failure and ejection fraction below $50 \%$.

\section{Materials and Methods}

\section{Data collection and analysis}

The data used in this study including age, gender, comorbidities and medical history of the patients were collected from the multicenter prospective registry of FARmacology and NeuroHumoraL activation (FAR NHL), between 1st October 2014 and 30th November 2015 in three cardiological centers in the Czech Republic with the help of heart failure specialists in the First Department of Internal Medicine Cardioangiology, St. Anne's University Hospital, Brno; Department of Internal Cardiology Medicine, University Hospital, Brno and Department of Cardiology, Na Homolce Hospital, Prague.

Outpatients and hospitalized patients with at least 30 days of stable chronic heart failure for over 18 years of age with LVEF under 50\% were included. Patients after Orthotopic Heart Transplant (OHT) or with Left Ventricle Assist Device (LVAD) implantation in the baseline were excluded. In November 2016, the follow-up data were collected directly from patients, hospital information systems and State Institute for Drug Control (SÚKL, Státní ústav pro kontrolu léčiv) including numbers and reasons of hospitalizations and deaths. Thus, all patients had at least one-year data from the time of recruitment, but up to two years after the time of follow-up. One-year data were used for the whole set of patients, data up to 24 months were used with Kaplan-Meier's survival curves of patient survival without presented endpoint.

The combined primary endpoint was considered to have been met if the patient experienced Acute Heart Failure (AHF) admission, all-cause mortality, LVAD implantation or OHT during the follow-up period.

As shown in Fig. 1, out of 1095 valid records in the FAR NHL database, 19 were without follow-up data, 529 patients were without available values of creatinine, NGAL or N-terminal pro-brain natriuretic peptide (NT-proBNP).

\section{Blood samples collection and analysis}

Samples of venous blood were collected from the patients to evaluate basic parameters. Blood samples for NGAL analyses were centrifuged within 10 minutes in a refrigerated centrifuge, and the plasma and serum were stored at $-80^{\circ} \mathrm{C}$. NGAL was analysed using Lipocalin-2/NGAL Human ELISA kits (BioVendor, Czechia). The limit of detection was $0.02 \mathrm{ng} / \mathrm{ml}$, calibration range was $0.3-10 \mathrm{ng} / \mathrm{ml}$, Intra-assay CV was $7.7 \%$ and Inter-assay $\mathrm{CV}$ was $9.8 \%$.

Plasma levels of NT-ProBNP were analysed using the Cobas E411 NT-proBNP Immunoassay Kit (Roche Diagnostics, Indianapolis, IN, USA).

\section{Statistical analysis}

Standard descriptive statistics was applied in the analysis; continuous variables were described by median supplemented with $5^{\text {th }}-95^{\text {th }}$ percentile range, and categorical variables were described by absolute and relative frequencies of categories. The association between continuous variables was evaluated by using the Spearman correlation coefficient and its statistical significance. The statistical significance of differences in continuous variables among groups of patients was evaluated by using Mann Whitney or Kruskal-Wallis test. Receiver Operating Characteristic (ROC) was performed to evaluate the individual predictive value of the marker for the combined endpoint and to determine their cutoff values. Multivariate logistic regression was computed to evaluate the combined influence of biomarkers. Kaplan-Meier's

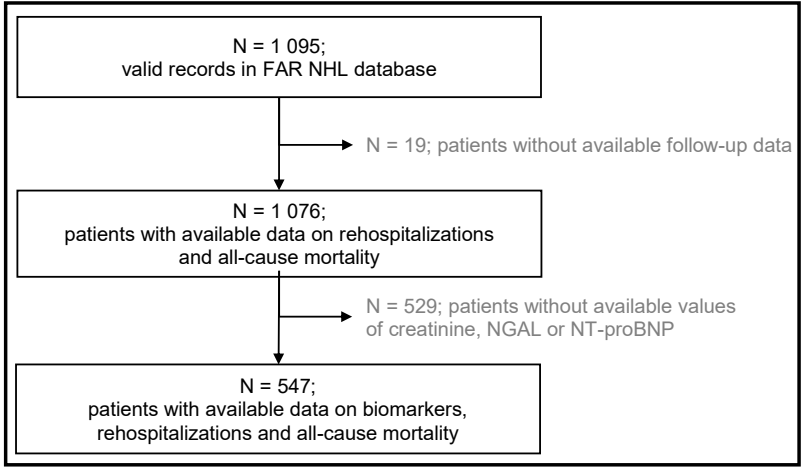

Fig. 1. Flowchart - selection of patients. 


\section{Kidney \\ Blood Pressure \\ Research}

Lábr et al.: NGAL and Prognosis in Chronic Heart Failure

curves were adopted for the visualisation of survival data; statistical significance of differences in survival was evaluated using the log-rank test. The level of statistical significance of 0.05 was used in all analyses. The analysis was computed by using SPSS 24.0.0.1 (IBM Corporation, 2017).

\section{Results}

\section{Baseline}

We studied 547 patients with available data on hospitalizations and mortality, out of whom 439 were males (80.3\%). Median of age was 66 years, blood pressure was 130/80 $\mathrm{mm} \mathrm{Hg}$, heart rate was 72 per minute while the median of Body Mass Index (BMI) was 29 $\mathrm{kg} / \mathrm{m}^{2}$. The rhythm in the baseline was at $65.1 \%$ sinus $(\mathrm{n}=356)$, at $14 \%$ atrial fibrillation $(n=80)$, while $20.3 \%$ of patients had stimulated rhythm $(n=111)$. The etiology of heart failure was ischemic heart disease in 53.6\% $(n=293)$ and Dilated Cardiomyopathy (DCM) in $39.9 \%(n=218)$. Patients were in NYHA functional class I in $12.8 \%(n=70)$, class II in $68.6 \%$ $(n=375)$ and classes III-IV in $18.6 \%(n=102)$.

Their comorbidities were diabetes mellitus in 40.6\% $(n=222)$ and Arial Fibrillation (AF) in $32.9 \%(n=180)$ while $45.5 \%$ of patients $(n=249)$ had previous myocardial infarction. Implanted Pacemaker (PM) or Implantable Cardioverter Defibrilator (ICD) was in $27.0 \%$ $(n=148)$ of patients.

The median level of sodium was $141 \mathrm{mmol} / \mathrm{L}$, potassium $4.5 \mathrm{mmol} / \mathrm{L}$, albumin $43 \mathrm{~g} / \mathrm{L}$, hemoglobin $144 \mathrm{~g} / \mathrm{L}$ and NTproBNP $631 \mathrm{pg} / \mathrm{mL}$. Renal parameters were as follows: median of urea $6.0 \mathrm{mmol} / \mathrm{L}$, creatinine $96 \mu \mathrm{mol} / \mathrm{L}, \mathrm{NGAL} 54$ $\mathrm{ng} / \mathrm{mL}$ and creatinine clearance according to MDRD formula was $70 \mathrm{~mL} / \mathrm{min} / 1.73 \mathrm{~m}^{2}$. The baseline characteristics are given in Table 1.

The results showed that $94 \%$ of all patients in FAR NHL received beta blockers, $88 \%$ angiotensinconverting-enzyme inhibitors or angiotensin II receptor blockers, $81 \%$ furosemide and $68 \%$ spironolactone or eplerenone [14].

\section{Associations between patients' characteristics and NGAL values}

The higher the age of the patient, the higher the NGAL value $(p<0.001)$ and the lower the blood pressure, the higher the NGAL value (SBP: $p=0.003$; DBP: $\mathrm{p}<0.001$ ). NGAL value was lower

Table 1. Baseline characteristics of patients in FAR NHL registry. Continuous variables are described by median (5th percentile; 95th percentile); categorical variables are characterized by absolute and relative frequencies. AF, atrial fibrillation; BMI, body mass index; DBP, diastolic blood pressure; DCM, dilated cardiomyopathy; ICD, implantable cardioverter defibrillator; IHD, ischaemic heart disease; LV EF, left ventricular ejection fraction; NGAL, neutrophil gelatinase-associated lipocalin NTproBNP, N-terminal pro-brain natriuretic peptide; $\mathrm{PM}$, pace maker; SBP, systolic blood pressure

\begin{tabular}{|c|c|c|}
\hline Parameter & Factor & Total $(\mathrm{N}=547)^{1}$ \\
\hline \multicolumn{3}{|l|}{ Basic characteristics } \\
\hline \multirow[t]{2}{*}{ Gender } & Man & $439(80.3 \%)$ \\
\hline & Woman & $108(19.7 \%)$ \\
\hline Age & & $66(43 ; 84)$ \\
\hline Weight & $(\mathrm{kg})$ & $88(62 ; 122)$ \\
\hline BMI & & $29(22 ; 38)$ \\
\hline SBP & $(\mathrm{mmHg})$ & $130(100 ; 155)$ \\
\hline DBP & $(\mathrm{mmHg})$ & $80(64 ; 100)$ \\
\hline Heart rate & $\left(\min ^{-1}\right)$ & $72(56 ; 96)$ \\
\hline \multirow[t]{3}{*}{ Rhythm } & Sinus & $356(65.1 \%)$ \\
\hline & $\mathrm{AF}$ & $80(14.6 \%)$ \\
\hline & Stimulated & $111(20.3 \%)$ \\
\hline \multirow[t]{3}{*}{ Etiology } & IHD & $293(53.6 \%)$ \\
\hline & DCM & $218(39.9 \%)$ \\
\hline & Other & $34(6.2 \%)$ \\
\hline \multirow[t]{3}{*}{ NYHA } & 1 & $70(12.8 \%)$ \\
\hline & 2 & $375(68.6 \%)$ \\
\hline & $3-4$ & $102(18.6 \%)$ \\
\hline LV EF & $(\%)$ & $30.0(18.0 ; 45.0)$ \\
\hline \multicolumn{3}{|l|}{ History } \\
\hline Diabetes mellitus & & $222(40.6 \%)$ \\
\hline Atrial fibrillation & & $180(32.9 \%)$ \\
\hline Myocardial infarction & & $249(45.5 \%)$ \\
\hline PM or ICD & & $148(27.0 \%)$ \\
\hline \multicolumn{3}{|l|}{ Laboratory } \\
\hline Natrium & $(\mathrm{mmol} / \mathrm{L})$ & $141(134 ; 146)$ \\
\hline Kalium & $(\mathrm{mmol} / \mathrm{L})$ & $4.5(3.8 ; 5.3)$ \\
\hline Albumin & $(\mathrm{g} / \mathrm{L})$ & $43(36 ; 49)$ \\
\hline Hemoglobin & $(\mathrm{g} / \mathrm{L})$ & $144(114 ; 167)$ \\
\hline NT-proBNP & $(\mathrm{pg} / \mathrm{mL})$ & $631(41 ; 5545)$ \\
\hline NGAL & $(\mathrm{ng} / \mathrm{mL})$ & $54(27 ; 153)$ \\
\hline Urea & $(\mathrm{mmol} / \mathrm{L})$ & $6.0(3.5 ; 15.2)$ \\
\hline Creatinine & $(\mu \mathrm{mol} / \mathrm{L})$ & $96(66 ; 184)$ \\
\hline Creatinine clearance (MDRD formula) & $\left(\mathrm{mL} / \mathrm{min} / 1.73 \mathrm{~m}^{2}\right)$ & $70(32 ; 107)$ \\
\hline
\end{tabular}




\section{Kidney \\ Blood Pressure Research}

in sinus rhythm than in $\mathrm{AF}$ or stimulated rhythm (52;62;61 ng/mL; $\mathrm{p}<0.001)$ and higher when the etiology of heart failure was ischemic (58 vs. 46 DCM, $p<0.001$ ). NYHA functional class I patients had much lower NGAL values than higher classes ( 41 vs. 56 or $55 \mathrm{ng} / \mathrm{mL}$; $<0.001$ ). There was no association between NGAL and gender and the weight of patient or LVEF.

Patients with diabetes mellitus, atrial fibrillation or after myocardial infarction had significantly higher NGAL values than those without these comorbidities.

Some of the patients characteristics were highly associated with NGAL, directly proportional were other kidney characteristics namely urea and creatinine, and also NTproBNP. Inversely proportional was creatinine clearance and also albumin and hemoglobin. Associations between patients' characteristics and NGAL values are shown in Table 2.

\section{Follow-up data}

The results of followup data showed that $13.9 \%$ of patients $(n=76)$ reached the primary endpoint events (all-cause mortality, AHF admissions, LVAD implantation and OHT) in the first 365 days of follow-up. Other events in the first year were all-cause death in 3.8\% $(\mathrm{n}=21)$, OHT and/or LVAD in $2.0 \% \quad(\mathrm{n}=11)$ and hospitalization for AHF in $10.1 \%(n=55)$. The proportion of patients who experienced different types of events during the first year of follow-up are presented in Table 3.

Patients without events had lower baseline NT-proBNP levels (482 pg/mL [35-4202]) than those with events (1964 pg/mL [224-15211], $\mathrm{p}<0.001)$. The borderline significant difference was in baseline creatinine levels (95 $\mu \mathrm{mol} / \mathrm{L}[65-175]$ vs. 101 $\mu \mathrm{mol} / \mathrm{L}$ [66-229], $\mathrm{p}=0.051$ ). Neither NGAL $(53 \mathrm{ng} / \mathrm{mL}$ [27-150] vs. $57 \mathrm{ng} / \mathrm{mL}$ [28$173], \mathrm{n}=0.191$ ) nor creatinine

Table 2. Associations between patients' characteristics and NGAL values. For categorical variables, median (5th percentile; 95th percentile) of NGALvalues is reported. Otherwise, Spearman's rank correlation coefficient is applied to measure association between continuous parameters and NGAL values. ${ }^{2} \mathrm{P}$-value of Kruskal-Wallis test or P-value for statistical significance of Spearman's coefficient is reported. AF, atrial fibrillation; BMI, body mass index; CRT, cardiac resynchronization therapy; DBP, diastolic blood pressure; DCM, dilated cardiomyopathy; ICD, implantable cardioverter defibrillator; IHD, ischaemic heart disease; LV EF, left ventricular ejection fraction; NT-proBNP, N-terminal pro-brain natriuretic peptide; PM, pace maker; SBP, systolic blood pressure

\begin{tabular}{|c|c|c|c|c|}
\hline Parameter & Factor & $\mathrm{N}$ & NGAL (ng/mL) ${ }^{1}$ & $\mathrm{P}^{2}$ \\
\hline \multicolumn{5}{|l|}{ Baseline characteristics } \\
\hline \multirow{2}{*}{ Gender } & Men & 445 & $54(27 ; 155)$ & \multirow{2}{*}{0.949} \\
\hline & Women & 112 & $52(25 ; 150)$ & \\
\hline Age & & 557 & 0.431 & $<0.001$ \\
\hline Weight & $(\mathrm{kg})$ & 553 & -0.067 & 0.117 \\
\hline BMI & & 553 & -0.059 & 0.169 \\
\hline SBP & (mmHg) & 557 & -0.126 & 0.003 \\
\hline DBP & $(\mathrm{mmHg})$ & 557 & -0.204 & $<0.001$ \\
\hline Heart rate & $\left(\min ^{-1}\right)$ & 557 & 0.087 & 0.040 \\
\hline \multirow[t]{3}{*}{ Rhythm } & Sinus & 361 & $50(26 ; 135)$ & \multirow{3}{*}{$<0.001$} \\
\hline & $\mathrm{AF}$ & 81 & $62(33 ; 173)$ & \\
\hline & Stimulated & 115 & $61(29 ; 165)$ & \\
\hline \multirow[t]{2}{*}{ DCM etiology } & Yes & 227 & $46(27 ; 134)$ & \multirow{2}{*}{$<0.001$} \\
\hline & Other & 330 & $58(27 ; 173)$ & \\
\hline \multirow[t]{2}{*}{ IHD etiology } & Yes & 298 & $58(28 ; 179)$ & \multirow{2}{*}{$<0.001$} \\
\hline & Other & 259 & $48(26 ; 139)$ & \\
\hline \multirow[t]{3}{*}{ NYHA } & 1 & 74 & $41(23 ; 108)$ & \multirow{3}{*}{$<0.001$} \\
\hline & 2 & 379 & $56(28 ; 174)$ & \\
\hline & $3-4$ & 104 & $55(26 ; 123)$ & \\
\hline LV EF & $(\%)$ & 557 & 0.007 & 0.876 \\
\hline \multicolumn{5}{|l|}{ History } \\
\hline \multirow[t]{2}{*}{ Diabetes mellitus } & Yes & 226 & $57(28 ; 174)$ & \multirow{2}{*}{0.006} \\
\hline & No & 331 & $51(27 ; 136)$ & \\
\hline \multirow[t]{2}{*}{ Atrial fibrillation } & Yes & 182 & $62(31 ; 181)$ & \multirow{2}{*}{$<0.001$} \\
\hline & No & 375 & $49(26 ; 134)$ & \\
\hline \multirow[t]{2}{*}{ Myocardial Infarction } & Yes & 251 & $59(28 ; 179)$ & \multirow{2}{*}{$<0.001$} \\
\hline & No & 306 & $49(27 ; 150)$ & \\
\hline \multirow[t]{2}{*}{ PM } & Yes & 36 & $87(40 ; 232)$ & \multirow{2}{*}{$<0.001$} \\
\hline & No & 521 & $52(27 ; 143)$ & \\
\hline \multirow[t]{2}{*}{ ICD and/or CRT } & Yes & 116 & $55(30 ; 154)$ & \multirow{2}{*}{0.179} \\
\hline & No & 441 & $53(27 ; 153)$ & \\
\hline \multicolumn{5}{|l|}{ Laboratory } \\
\hline Urea & $(\mathrm{mmol} / \mathrm{L})$ & 556 & 0.443 & $<0.001$ \\
\hline Natrium & $(\mathrm{mmol} / \mathrm{L})$ & 556 & -0.055 & 0.193 \\
\hline Kalium & $(\mathrm{mmol} / \mathrm{L})$ & 323 & 0.110 & 0.049 \\
\hline Albumin & $(\mathrm{g} / \mathrm{L})$ & 516 & -0.232 & $<0.001$ \\
\hline Hemoglobin & (g/L) & 557 & -0.237 & $<0.001$ \\
\hline NT-proBNP & $(\mathrm{pg} / \mathrm{mL})$ & 550 & 0.260 & $<0.001$ \\
\hline Creatinine & $(\mu \mathrm{mol} / \mathrm{L})$ & 557 & 0.532 & $<0.001$ \\
\hline $\begin{array}{l}\text { Creatinine clearance } \\
\text { (Cockcroft-Gault formula) }\end{array}$ & $\left(\mathrm{mL} / \mathrm{min} / 1.73 \mathrm{~m}^{2}\right)$ & 553 & -0.582 & $<0.001$ \\
\hline $\begin{array}{l}\text { Creatinine clearance } \\
\text { (MDRD formula) }\end{array}$ & $\left(\mathrm{mL} / \mathrm{min} / 1.73 \mathrm{~m}^{2}\right)$ & 557 & -0.560 & $<0.001$ \\
\hline
\end{tabular}




\section{Kidney \\ Blood Pressure \\ Research}

clearance $\left(71 \mathrm{~mL} / \mathrm{min} / 1.73 \mathrm{~m}^{2}\right.$ [33-106] vs. $68 \mathrm{~mL} / \mathrm{min} / 1.73 \mathrm{~m}^{2}$ [23-110], $\mathrm{n}=0.228$ ) was significantly different between patients without and with events. Relationship between baseline biomarkers and presence of the primary endpoint in the first year of follow-up is shown in Table 4 and Fig. 2.

\section{Analyses}

For categorical variables, median (5th percentile; 95th percentile) of NGALvalueswasreported. Otherwise, the Spearman's rank correlation coefficient was applied to measure the association between continuous parameters and NGAL values. KruskalWallis test was applied for statistical significance of continuous parameters differences between groups of patients.

The area under the receiver operating characteristic (ROC) curve was higher for NT-proBNP (0.77) than creatinine (0.57), NGAL (0.55) or creatinine clearance (0.54). Multivariate logistic regression was performed to combine the influence of NT-proBNP and NGAL (area under the curve $=0.76$ ) as
Table 3. Proportion of patients who experienced different types of events in the first year of follow-up ( $\mathrm{N}=547)$. ACS, acute coronary syndrome; AHF, acute heart failure; IHD, ischaemic heart disease; LVAD, left ventricular assist device; OHT, orthotopic heart transplant; PM, pace maker, ICD Implantable cardioverter-defibrillator

\begin{tabular}{lc}
\hline Events in the first year of follow-up & No. of patients (\%) \\
\hline Primary endpoint (death/hospitalization for AHF/LVAD/OHT) & $76(13.9 \%)$ \\
Death & $21(3.8 \%)$ \\
Cardiovascular-related hospitalization & $117(21.4 \%)$ \\
AHF & $55(10.1 \%)$ \\
ACS & $5(0.9 \%)$ \\
Arrhythmia & $19(3.5 \%)$ \\
Cerebrovascular disease & $7(1.3 \%)$ \\
IHD & $7(1.3 \%)$ \\
Peripheral artery disease & $5(0.9 \%)$ \\
PM/ICD implantation & $23(4.2 \%)$ \\
OHT and/or LVAD & $11(2.0 \%)$ \\
Cardiovascular-related hospitalization and/or death & $131(23.9 \%)$ \\
All-cause hospitalization (excl. diagnostic hospitalizations) and/or death & $171(31.3 \%)$ \\
All-cause hospitalization and/or death & $181(33.1 \%)$ \\
\hline
\end{tabular}

Table 4. Relationship between baseline biomarkers and primary end-point in the first year of follow-up (death, hospitalization for AHF, LVAD, OHT). Biomarker values are described by median (5th percentile; 95th percentile). ${ }^{1} \mathrm{P}$-value of Mann-Whitney U test. AHF, acute heart failure; LVAD, left ventricular assist device; OHT, orthotopic heart transplant; NGAL, neutrophil gelatinase-associated lipocalin NTproBNP, N-terminal pro-brain natriuretic peptide

\begin{tabular}{|c|c|c|c|c|}
\hline Biomarker & $\begin{array}{c}\text { Total } \\
(\mathrm{N}=547)\end{array}$ & $\begin{array}{c}\text { Endpoint - no } \\
(\mathrm{N}=471)\end{array}$ & $\begin{array}{c}\text { Endpoint - yes } \\
(\mathrm{N}=76)\end{array}$ & $\mathrm{P}^{1}$ \\
\hline NGAL (ng/mL) & $54(27 ; 153)$ & $53(27 ; 150)$ & $57(28 ; 173)$ & 0.191 \\
\hline NT-proBNP $(\mathrm{pg} / \mathrm{mL})$ & $631(41 ; 5545)$ & $482(35 ; 4202)$ & $1964(224 ; 15211)$ & $<0.001$ \\
\hline Creatinine $(\mu \mathrm{mol} / \mathrm{L})$ & $96(66 ; 184)$ & $95(65 ; 175)$ & $101(66 ; 229)$ & 0.051 \\
\hline Creatinine clearance $(\mathrm{mL} / \mathrm{min} / 1.73 \mathrm{~m} 2)$ & $70(32 ; 107)$ & $71(33 ; 106)$ & $68(23 ; 110)$ & 0.228 \\
\hline
\end{tabular}

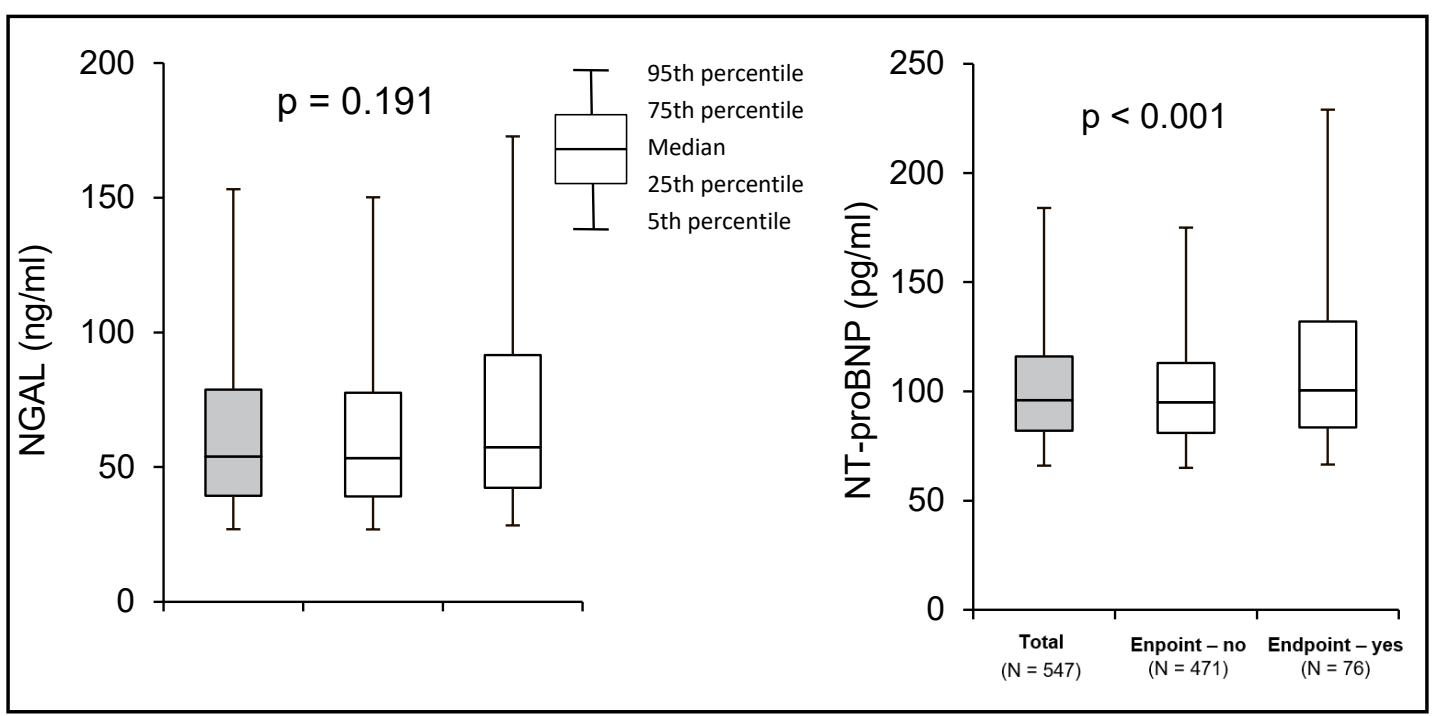

Fig. 2. Distribution of NGAL and NT-proBNP values. NGAL, neutrophil gelatinase-associated lipocalin, NTproBNP, N-terminal pro-brain natriuretic peptide. 


\section{Kidney Blood Pressure Research}

Fig. 3. ROC curves for prediction of 1-year primary endpoint occurrence (death, hospitalization for AHF, LVAD or OHT). AHF, acute heart failure; LVAD, left ventricular assist device; OHT, orthotopic heart transplant; NGAL, neutrophil gelatinase-associated lipocalin NT-proBNP, N-terminal pro-brain natriuretic peptide.

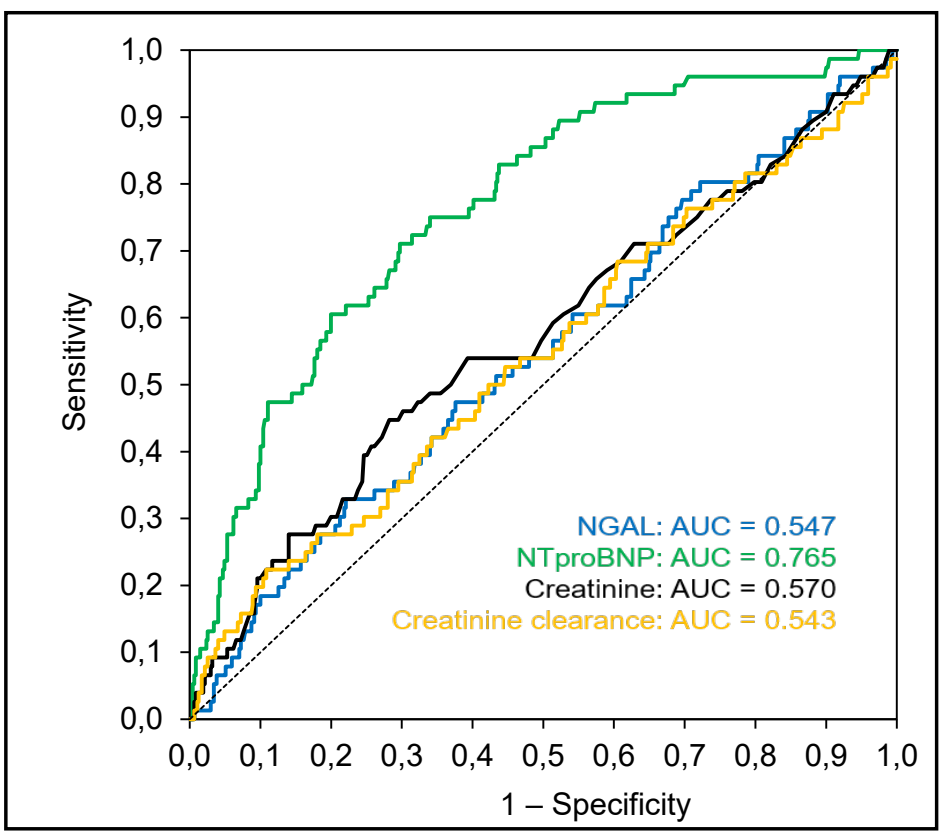

Fig. 4. ROC curves for prediction of 1-year primary endpoint occurrence (death, hospitalization for AHF, LVAD or OHT). AHF, acute heart failure; LVAD, left ventricular assist device; OHT, orthotopic heart transplant; NGAL, neutrophil gelatinase-associated lipocalin; NT-proBNP, N-terminal pro-brain natriuretic peptide.

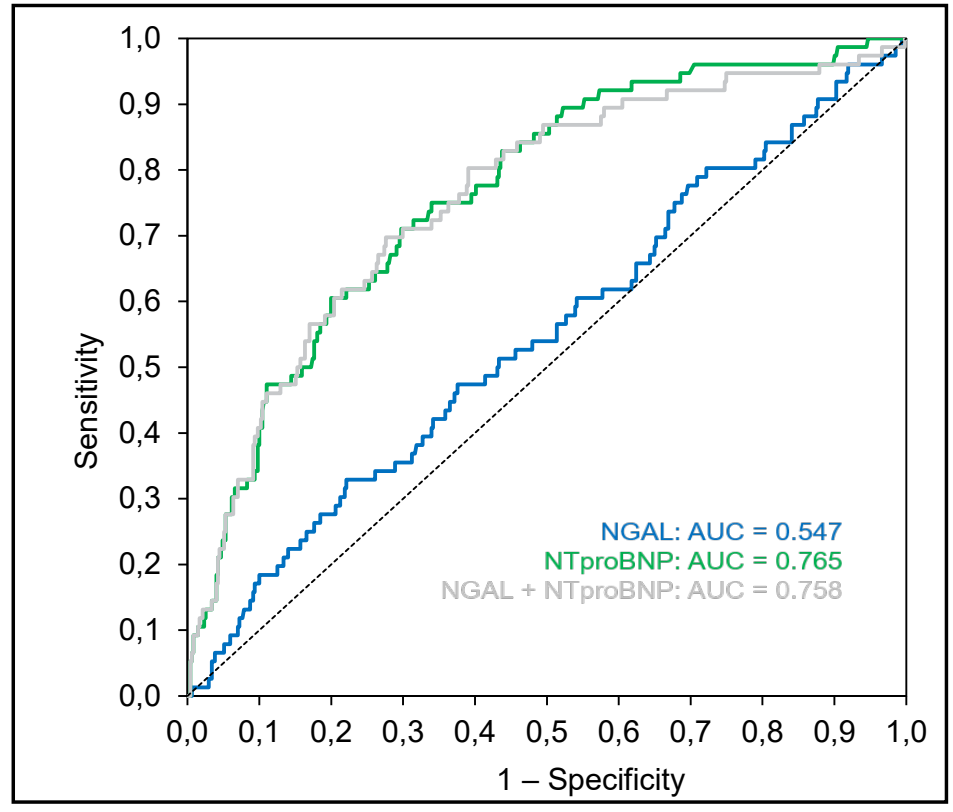

presented in Fig. 3 and 4. The biomarkers were set at cutoff values, sensitivity and specificity as shown in Table 5. In NGAL, the cutoff value was $81 \mathrm{ng} / \mathrm{mL}$, the low sensitivity of $32.9 \%$ and specificity of $77.9 \%$ while in NT-proBNP, the cutoff value was $1122 \mathrm{pg} / \mathrm{mL}$ with a sensitivity of $71.1 \%$ and specificity of $70.3 \%$.

Using the cutoff values from ROC (NGAL $80 \mathrm{ng} / \mathrm{ml}$, NT-proBNP 1, $121 \mathrm{pg} / \mathrm{ml}$ ), in multivariable analyses, NT-proBNP $(\mathrm{p}=0.001)$ and NGAL $(\mathrm{p}=0.004)$ were significant predictors of events as shown in Fig. 5 and 6.

Subjects with both NGAL and NT-proBNP above the cutoff values survived without any event in 55.7\% while subjects with both NT-proBNP and NGAL below the cut-off value survived without primary endpoint in $90.5 \%$ after two years $(p=0,001)$ as shown in Fig. 7. 


\section{Kidney Blood Pressure Research}

Table 5. ROC analysis of biomarker abilities to predict primary outcome in the first year of follow-up. ${ }^{1}$ Multivariate logistic regression was performed to combine influence of both biomarkers. NGAL, neutrophil gelatinase-associated lipocalin NT-proBNP, N-terminal pro-brain natriuretic peptide

\begin{tabular}{lccccc}
\hline Biomarker & AUC $(95 \%$ IS) & P & Cutoff & Sensitivity & Specificity \\
\hline NGAL $(\mathrm{ng} / \mathrm{mL})$ & $0.547(0.475 ; 0.618)$ & 0.191 & $\geq 81$ & $32.9 \%$ & $77.9 \%$ \\
NT-proBNP $(\mathrm{pg} / \mathrm{mL})$ & $0.765(0.709 ; 0.822)$ & $<0.001$ & $\geq 1122$ & $71.1 \%$ & $70.3 \%$ \\
Creatinine $(\mu \mathrm{mol} / \mathrm{L})$ & $0.570(0.496 ; 0.644)$ & 0.051 & $\geq 109$ & $44.7 \%$ & $71.8 \%$ \\
Creatinine clearance $(\mathrm{mL} / \mathrm{min} / 1.73 \mathrm{~m} 2)$ & $0.543(0.469 ; 0.617)$ & 0.228 & $\leq 43$ & $22.4 \%$ & $89.2 \%$ \\
NGAL $(\mathrm{ng} / \mathrm{mL})+$ NTproBNP $(\mathrm{pg} / \mathrm{mL})^{1}$ & $0.758(0.698 ; 0.818)$ & $<0.001$ & - & $69.7 \%$ & $72.4 \%$ \\
\hline
\end{tabular}

Fig. 5. Primary endpoint (death, hospitalization for AHF, OHT or LVAD) according to NGAL. AHF, acute heart failure; LVAD, left ventricular assist device; OHT, orthotopic heart transplant; NGAL, neutrophil gelatinase-associated lipocalin.

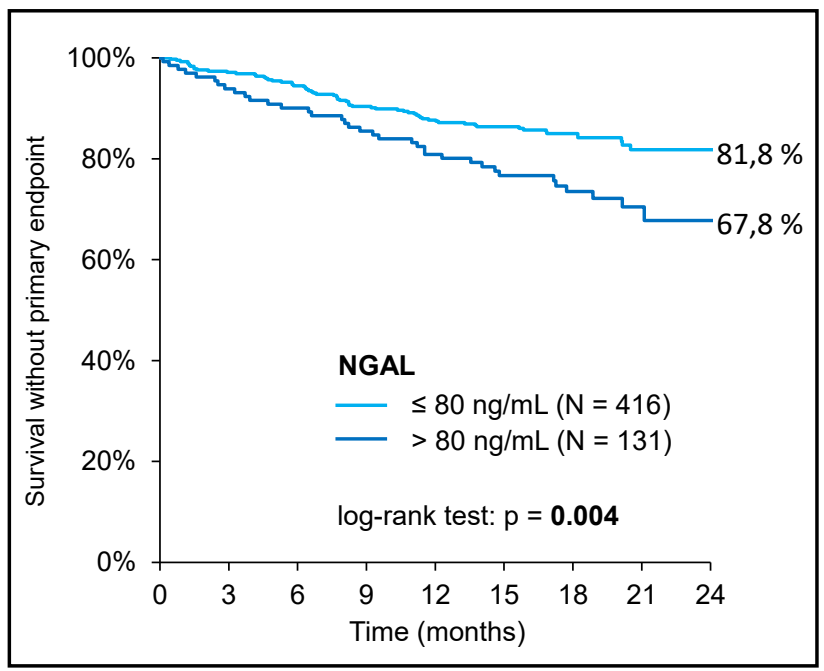

Fig. 6. Primary endpoint (death, hospitalization for AHF, OHT or LVAD) according to NT-proBNP. AHF, acute heart failure; LVAD, left ventricular assist device; OHT, orthotopic heart transplant; NTproBNP, N-terminal pro-brain natriuretic peptide.

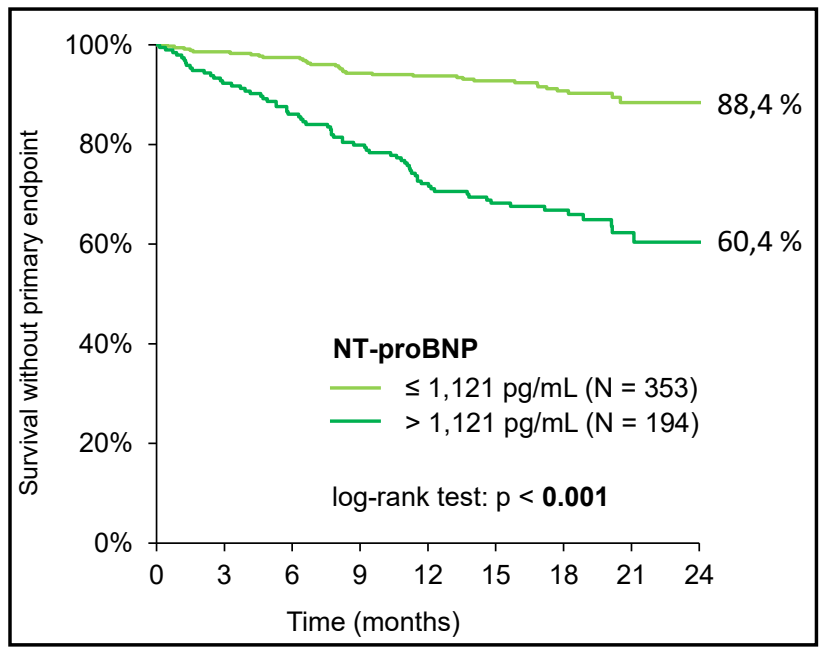

\section{Discussion}

This paper summarizes the baseline characteristics of patients with heart failure with reduced ejection fraction from three university hospitals in the Czech Republic and the data from follow-up made in one year after finishing of recruitment in such a way that some patients had data that were up to two years of follow-up from beginning of recruitment. 


\section{Kidney Blood Pressure Research}

Fig. 7. Primary endpoint (death, hospitalization for AHF, OHT or LVAD) according to NGAL and NT-proBNP in chronic heart failure patients (FAR NHL).AHF, acute heart failure; LVAD, left ventricular assist device; OHT, orthotopic heart transplant; NGAL, neutrophil gelatinase-associated lipocalin NT-proBNP, N-terminal pro-brain natriuretic peptide.

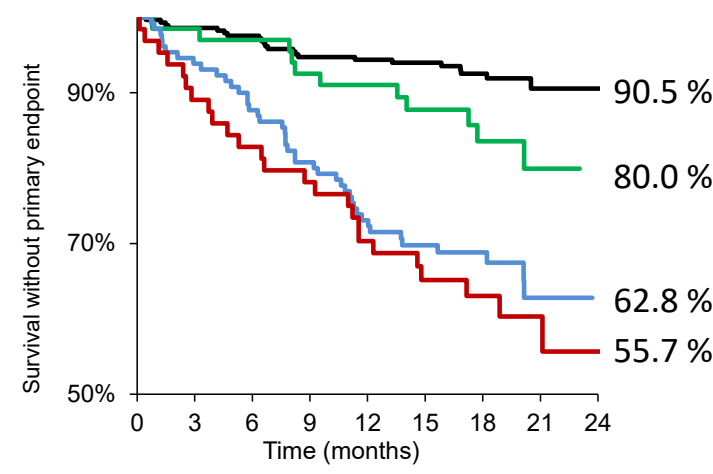

NGAL + NTproBNP:

log-rank test: $p<0.001$

- NGAL $\leq 80 \mathrm{ng} / \mathrm{mL}+\mathrm{NTproBNP} \leq 1,121 \mathrm{pg} / \mathrm{mL}(\mathrm{N}=286)$

- NGAL $>80 \mathrm{ng} / \mathrm{mL}+\mathrm{NTproBNP} \leq 1,121 \mathrm{pg} / \mathrm{mL}(\mathrm{N}=67)$

- NGAL $\leq 80 \mathrm{ng} / \mathrm{mL}+\mathrm{NTproBNP}>1,121 \mathrm{pg} / \mathrm{mL}(\mathrm{N}=130)$

- NGAL $>80 \mathrm{ng} / \mathrm{mL}+\mathrm{NTproBNP}>1,121 \mathrm{pg} / \mathrm{mL}(\mathrm{N}=64)$

In the recently published European ESC-HF-LT registry, comparison of acute and chronic heart failure with mortality from all causes was $6.4 \%$ for chronic heart failure, in contrast to the much lower value of $3.8 \%$ in our registry. The number of those that were hospitalized in one year due to heart failure was compared to the numbers in the European registry $(9.9 \%)$ and FAR NHL (10.1\%). There were large differences between various regions in Europe where the lowest mortality rates were in the southern and western Europe with 6.9 and $7.6 \%$ respectively [15]. In our registry, even if mortality (3.8\%) was added to patients that underwent OHT and / or LVAD implantation (2.0\%), we would still have the lowest mortality rate in CHF patients, though, we had more severe patients waiting for OHT.

In FAR NHL registry, there was a very high ratio between men and women $(80.3 \%$ vs. $19.7 \%$ ) and even in clinical trials, CHF always predominated in men. In Brno transplant center, where one of the inclusion criteria for heart transplantation is age greater than 65 years, women at this age were far less represented than men in the heart failure group with the aetiology of ischemic heart disease. In women, ischemic heart disease was more prevalent at older age. A similar representation of men and women is reported in the MERITHF study [16].

Our registry had one group of patients with LVEF less than $50 \%$ after the conclusion of recruitment. Based on HF guidelines, patients were separated into two groups, namely heart failure with reduced ejection fraction (HFrEF) and heart failure with mid-ranged ejection fraction (HFmrEF). A Swedish study shows that stage of Chronic Kidney Disease (CKD) is far more associated with the death of patients than with these patients (HFrEF and HFmrEF) and than with heart failure with preserved ejection fraction (HFpEF) patients [17]. Therefore, these patients from our registry with ejection fraction less than $50 \%$ were not divided into these two categories.

As a Dutch study shows that renal function is a better predictor of mortality in patients with advanced CHF than the reduced LVEF or NYHA class, it similarly predicts mortality with natriuretic peptides [3]. According to another Dutch study, the largest association with the mortality of patients with heart failure is renal function and natriuretic peptides [18]. So we chose renal biomarker NGAL and NT-proBNP to try the prediction of events in CHF.

Recently, a small single-centre retrospective study from Turkey also shows that plasma NGAL levels can be reliably used in patients who underwent on-pump CABG for early diagnosis of kidney dysfunction [19]. In a group analysis of cardiac surgery patients, the highest NGAL values were associated with greater odds of advanced AKI, but not linear. The elevated level of NGAL in other kidney biomarkers predicted the outcomes of hospitalization and increased mortality regardless of the presence of advanced AKI [20]. In a retrospective 


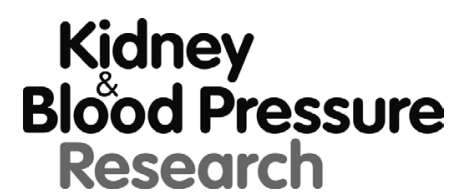

study of NGAL and AKI association in cardiac arrest survivors, NGAL level at 48 hours was a more significant predictor with a higher area under ROC than NGAL level after the return of spontaneous circulation. Both NGAL levels were associated with a high stage of AKI [21]. This tells us that NGAL plasma levels change rapidly after a few hours of an event (cardiac arrest, in this case). There were more significant values after 48 hs but the NGAL level at 48 $\mathrm{h}$ was also a significant predictor of mortality in this study.

In the GISSI-HF study, urinary NGAL is primarily associated with higher mortality risk, but not with a higher incidence of HF hospitalizations. This seems to be consistent with the knowledge that NGAL may be a less specific tubular marker and is more a marker of the overall (cardiovascular) severity of the disease. Conversely, other new renal markers (NAG and KIM-1) showed a similar mortality and hospitalization risk estimation [13].

In a Dutch study, loop diuretics were discontinued for $72 \mathrm{~h}$ in stable CHF patients and the levels of the novel and standard renal biomarkers were measured while urinary and serum NGAL as the only renal biomarker was not significantly changed. This makes NGAL a marker independent of congestion [22]. In our stable patients with no congestion, NGAL level was significantly higher, as well as the level of NT-proBNP. This could be caused by the elevation of both markers when other comorbidities are present.

NGAL had low sensitivity and high specificity in our registry. This is probably due to the rise in NGAL in patients with other chronic diseases such as tumors, stroke, hypertension, systemic inflammatory diseases, anemia and ischemia $[23,24]$.

In the study of Maisel et al. (GALLANT), it was reported that the levels of NGAL combined with a natriuretic peptide are prognostic for adverse outcomes in AHF [25]. When compared FAR NHL Kaplan-Meier plot of events for NGAL and NT-proBNP that contains CHF patients (Fig. 7) to GALLANT study Kaplan-Meier plot with AHF patients, there were some similarities. In both studies, the highest survival rate without primary endpoint was at the values of both biomarkers (NGAL and natriuretic peptides) below the cutoff values. The low survival rate was at the levels of both biomarkers higher than cutoff values. However, the other two curves were different. While there were higher survival rates for AHF (GALLANT) patients with NGAL lower than the cutoff value and natriuretic peptide higher than the cutoff value, it is the opposite in the case of CHF (FAR NHL). This indicates that NGAL might be a more significant marker in AHF and natriuretic peptides might be a more significant prognostic marker in CHF.

In the CORONA study with rosuvastatin in CHF elderly patients of ischemic etiology receiving standard pharmacological treatment, serum NGAL has shown to be predictive of overall mortality and death from cardiovascular causes. Anyway, other markers may have more prognostic information [12]. In FAR NHL, there were higher rates of dilated cardiomyopathies and more severe heart failure due to the inclusion of the First Department of Cardioangiology, St. Anne's University Hospital, Brno, which is one of two centers in the Czech Republic involved in heart transplantation. Therefore, we had over $40 \%$ of dilated cardiomyopathy in our registry. NGAL was significantly higher in ischemic etiology than in dilated cardiomyopathy, therefore a lower cutoff value was considered in these patients.

Recent study showed that multiparametric or multi-biomarker approach is the best method to stratify prognosis. In a long-term registry of chronic heart failure, patients with reduced ejection fraction were compared to multiparametric prognostic scores, and the MECKI (Metabolic Excercise test data combined with Cardiac and Kidney Indexes) score was superior to other tested scores [26]. Also, regarding our registry, NGAL should be included in the multi-biomarker approach to set prognosis more precisely.

A current article [7] summarizing information on biomarkers of renal impairment and function stated that these markers have prognostic information but are not always additive to established markers of renal function. Their role in the prediction of renal impairment is limited at best. This also applies to NGAL in our registry where NGAL alone had only a small additive value but in conjunction with NT-proBNP, it had a better ability to predict events. At present, the best evidence is still for serum creatinine in combination with glomerular 


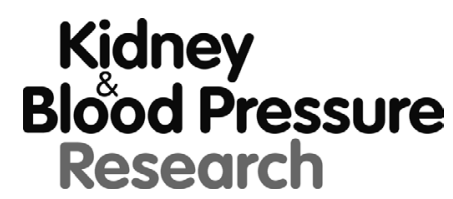

Kidney Blood Press Res 2018;43:1865-1877

\begin{tabular}{|l|l|l|}
\hline DOI: 10.1159/000495819 & (c) 2018 The Author(s). Published by S. Karger AG, Basel \\
\hline
\end{tabular}

Published online: 8 December 2018

www.karger.com/kbr

Lábr et al.: NGAL and Prognosis in Chronic Heart Failure

filtration. Current renal biomarkers can determine cardiovascular risk, but the therapy will not change according to the level of these biomarkers.

Recent publications also presented at Heart Failure Congress in Vienna 2018 showed that the biomarker-guided therapy recommended by American Heart Association [27], based on a golden biomarker of heart failure natriuretic peptides in AHF patients, has failed. The PRIMA II trial (Can NT-ProBNP-Guided Therapy During Hospital Admission for Acute Decompensated Heart Failure Reduce Mortality and Readmissions?) demonstrated that the guidance of HF therapy to reach an NT-proBNP reduction of $>30 \%$ after clinical stabilization did not improve 6-month outcomes [28]. The trial should continue and we should wait for a longer follow-up. More trials should be made to set the appropriate approach to the biomarker-guided therapy.

A recent study presented in Heart Failure Congress in Rome 2017 showed that patients with elevation of serum creatinine at the end of intravenous diuretic therapy of hospitalized acute heart failure have a better outcome than patients without elevation of serum creatinine [29]. It was explained that these patients are at the end of hospitalization and better compensated with less residual fluid congestion. And as we know, NGAL level is almost $48 \mathrm{~h}$ earlier as a biomarker than creatinine $[10,11]$, so it could be more useful for setting the time for the end of intravenous diuretic therapy.

\section{Conclusion}

The findings according to FAR NHL showed that both creatine and NGAL had a poor ability to predict a one-year primary endpoint (all-cause death, hospitalization for AHF, LVAD or OHT). NGAL in conjunction with NT-proBNP was important for the stratification of the primary endpoint. For chronic heart failure, the prognostic significance of NT-proBNP was prominent. NGAL could be higher when other comorbidities such as hypertension, diabetes mellitus, ischemic heart disease, anemia, hypoalbuminemia, arrhythmias, or stimulated rhythm are present.

\section{Limitations}

The FAR NHL cohort is a Czech multicentric prospective cohort which might not resemble the heterogeneity of the European patient population. There could be variations between the three different hospitals, especially St. Anne's University Hospital treats patients before OHT, so there were more severe heart failure patients than in the other two centers. This might influence the outcome and prediction. Basic laboratory measurements including NT-proBNP were not performed in a core laboratory and are subject to between-laboratory variability. NGAL levels were performed in one laboratory.

All the patients were Caucasian which reflects the population of the Czech Republic. It limits the generalizability of the models.

We assessed plasma NGAL, rather than urinary NGAL, which might be more affected by specific confounders, such as bacterial infection, the presence of cancer or chronic obstructive pulmonary disease, and inflammation while we had the advantage of the easy collection because plasma had already been collected in the clinical setting.

Patients were enrolled only from among those admitted to cardiology wards or seen in cardiology outpatient clinics, thus not considering HF patients seen in other units, such as emergency or other clinics and departments.

Finally, because of the short follow-up of the registry, the long-term changes were much expressed. We plan additional collection of the follow-up data in three years after registration. 


\section{Kidney \\ Blood Pressure Research}

Lábr et al.: NGAL and Prognosis in Chronic Heart Failure

\section{Disclosure Statement}

The authors have no conflicts of interest with this study.

\section{References}

1 Ponikowski P, Voors AA, Anker SD, Bueno H, Cleland JGF, Coats AJS, Falk V, González-Juanatey JR, Harjola VP, Jankowska EA, Jessup M, Linde C, Nihoyannopoulos P, Parissis JT, Pieske B, Riley JP, Rosano GMC, Ruilope LM, Ruschitzka F, Rutten FH, et al.: 2016 ESC Guidelines for the diagnosis and treatment of acute and chronic heart failure. Eur Heart J 2016;37:2129-2200.

2 Mosterd A, Hoes AW: Clinical epidemiology of heart failure. Heart Br Card Soc 2007;93:1137-1146.

-3 Hillege HL, Girbes AR, de Kam PJ, Boomsma F, de Zeeuw D, Charlesworth A, Hampton JR, van Veldhuisen DJ: Renal function, neurohormonal activation, and survival in patients with chronic heart failure. Circulation 2000;102:203-210.

4 Spinar J, Ludka O, Dusek L, Vitovcova L, Sobotova D, Spinarova L, Tomandl J, Vitovec J: Neurohumoral activity, heart failure and prognosis in patients with end-stage renal disease treated by hemodialysis. Kidney Blood Press Res 2007;30:347-357.

5 Shrestha K, Shao Z, Singh D, Dupont M, Tang WHW: Relation of systemic and urinary neutrophil gelatinase-associated lipocalin levels to different aspects of impaired renal function in patients with acute decompensated heart failure. Am J Cardiol 2012;110:1329-1335.

6 Haase-Fielitz A, Haase M, Devarajan P: Neutrophil gelatinase-associated lipocalin as a biomarker of acute kidney injury: a critical evaluation of current status. Ann Clin Biochem 2014;51:335-351.

7 van Veldhuisen DJ, Ruilope LM, Maisel AS, Damman K: Biomarkers of renal injury and function: diagnostic, prognostic and therapeutic implications in heart failure. Eur Heart J 2016;37:2577-2585.

>8 Helánová K, Pařenica J, Dlouhý V, Pávková Goldbergová M, Čermáková Z, Gottwaldová J, Špinar J: Význam biomarkerů NGAL a cystatinu C u kardiovaskulárních onemocnění. Vnitr Lek 2012;58:286-290.

9 Přeček J, Hutyra M, Kováčik F, Orság J, Táborský M: Biomarkery renálních funkcí v prognostické stratifikaci pacientů s akutním koronárním syndromem. Cor et Vasa 2018;60:e148-e154.

10 Mishra J, Dent C, Tarabishi R, Mitsnefes MM, Ma Q, Kelly C, Ruff SM, Zahedi K, Shao M, Bean J, Mori K, Barasch J, Devarajan P: Neutrophil gelatinase-associated lipocalin (NGAL) as a biomarker for acute renal injury after cardiac surgery. Lancet Lond Engl 2005;365:1231-1238.

11 Dent CL, Ma Q, Dastrala S, Bennett M, Mitsnefes MM, Barasch J, Devarajan P: Plasma neutrophil gelatinaseassociated lipocalin predicts acute kidney injury, morbidity and mortality after pediatric cardiac surgery: a prospective uncontrolled cohort study. Crit Care Lond Engl 2007;11:R127.

12 Nymo SH, Ueland T, Askevold ET, Flo TH, Kjekshus J, Hulthe J, Wikstrand J, McMurray J, Van Veldhuisen DJ, Gullestad L, Aukrust P, Yndestad A: The association between neutrophil gelatinase-associated lipocalin and clinical outcome in chronic heart failure: results from CORONA. J Intern Med 2012;271:436-443.

-13 Damman K, Masson S, Hillege HL, Maggioni AP, Voors AA, Opasich C, van Veldhuisen DJ, Montagna L, Cosmi F, Tognoni G, Tavazzi L, Latini R: Clinical outcome of renal tubular damage in chronic heart failure. Eur Heart J 2011;32:2705-2712.

14 Lábr K, Špinar J, Pařenica J, Špinarová L, Málek F, Špinarová M, Ludka O, Jarkovský J, Benešová K, Lábrová R: Betablokátory v registru chronického srdečního selhání FAR NHL. Kardiol Rev Int Med 2017;19:68-72.

15 Crespo-Leiro MG, Anker SD, Maggioni AP, Coats AJ, Filippatos G, Ruschitzka F, Ferrari R, Piepoli MF, Jimenez JFD, Metra M, Fonseca C, Hradec J, Amir O, Logeart D, Dahlstrom U, Merkely B, Drozdz J, Goncalvesova E, Hassanein M, et al.: European Society of Cardiology Heart Failure Long-Term Registry (ESC-HF-LT): 1-year follow-up outcomes and differences across regions. Eur J Heart Fail 2017;19:438-438.

$\$ 16$ MERIT-HF Study Group: Effect of metoprolol CR/XL in chronic heart failure: Metoprolol CR/XL Randomised Intervention Trial in-Congestive Heart Failure (MERIT-HF). The Lancet 1999;353:2001-2007.

17 Lofman I, Szummer K, Dahlstrom U, Jernberg T, Lund LH: Associations with and prognostic impact of chronic kidney disease in heart failure with preserved, mid-range, and reduced ejection fraction. Eur J Heart Fail 2017;19:1606-1614.

18 Voors AA, Ouwerkerk W, Zannad F, van Veldhuisen DJ, Samani NJ, Ponikowski P, Ng LL, Metra M, ter Maaten 


\section{Kidney \\ Blood Pressure Research}

Lábr et al.: NGAL and Prognosis in Chronic Heart Failure

JM, Lang CC, Hillege HL, van der Harst P, Filippatos G, Dickstein K, Cleland JG, Anker SD, Zwinderman AH: Development and validation of multivariable models to predict mortality and hospitalization in patients with heart failure. Eur J Heart Fail 2017;19:627-634.

19 Balkanay 00, Goksedef D, Omeroglu SN, Ipek G: The Reliability of the Use of Serum Neutrophil GelatinaseAssociated Lipocalin Levels in the Assessment of Renal Functions after Coronary Artery Bypass Grafting. Cardiol Res Pract 2018;7291254.

-20 Lin H, Scherzer R, Philbrook HT, Coca SG, Wilson FP, Garg AX, Shlipak MG, Parikh CR: Group analysis identifies differentially elevated biomarkers with distinct outcomes for advanced acute kidney injury in cardiac surgery. Biomark Med 2017;11:1091-1102.

-21 Cho YS, Lee BK, Lee DH, Jung YH, Lee SM, Park JS, Jeung KW: Association of plasma neutrophil gelatinaseassociated lipocalin with acute kidney injury and clinical outcome in cardiac arrest survivors depends on the time of measurement. Biomarkers 2018;23:487-494.

-22 Damman K, Chuen MJNK, MacFadyen RJ, Lip GYH, Gaze D, Collinson PO, Hillege HL, van Oeveren W, Voors AA, van Veldhuisen DJ: Volume Status and Diuretic Therapy in Systolic Heart Failure and the Detection of Early Abnormalities in Renal and Tubular Function. J Am Coll Cardiol 2011;57:2233-2241.

-23 Devarajan P: The promise of biomarkers for personalized renal cancer care. Kidney Int 2010;77:755-757.

24 Malyszko J, Bachorzewska-Gajewska H, Malyszko JS, Pawlak K, Dobrzycki S: Serum neutrophil gelatinaseassociated lipocalin as a marker of renal function in hypertensive and normotensive patients with coronary artery disease. Nephrology 2008;13:153-156.

25 Maisel AS, Mueller C, Fitzgerald R, Brikhan R, Hiestand BC, Iqbal N, Clopton P, van Veldhuisen DJ: Prognostic utility of plasma neutrophil gelatinase-associated lipocalin in patients with acute heart failure: The NGAL EvaLuation Along with B-type NaTriuretic Peptide in acutely decompensated heart failure (GALLANT) trial. Eur J Heart Fail 2011;13:846-851.

-26 Agostoni P, Paolillo S, Mapelli M, Gentile P, Salvioni E, Veglia F, Bonomi A, Corrà U, Lagioia R, Limongelli G, Sinagra G, Cattadori G, Scardovi AB, Metra M, Carubelli V, Scrutinio D, Raimondo R, Emdin M, Piepoli M, Magrì D, et al.: Multiparametric prognostic scores in chronic heart failure with reduced ejection fraction: a long-term comparison. Eur J Heart Fail 2018;20:700-710.

27 Chow SL, Maisel AS, Anand I, Bozkurt B, de Boer RA, Felker GM, Fonarow GC, Greenberg B, Januzzi JL, Kiernan MS, Liu PP, Wang TJ, Yancy CW, Zile MR, American Heart Association Clinical Pharmacology Committee of the Council on Clinical Cardiology; Council on Basic Cardiovascular Sciences; Council on Cardiovascular Disease in the Young; Council on Cardiovascular and Stroke Nursing; Council on Cardiopulmonary, Critical Care, Perioperative and Resuscitation; Council on Epidemiology and Prevention; et al.: Role of Biomarkers for the Prevention, Assessment, and Management of Heart Failure: A Scientific Statement From the American Heart Association. Circulation 2017;135:e1054-e1091.

-28 Stienen S, Salah K, Moons AH, Bakx AL, van Pol P, Kortz RAM, Ferreira JP, Marques I, Schroeder-Tanka JM, Keijer JT, Bayés-Genis A, Tijssen JGP, Pinto YM, Kok WE: NT-proBNP (N-Terminal pro-B-Type Natriuretic Peptide)-Guided Therapy in Acute Decompensated Heart Failure: PRIMA II Randomized Controlled Trial (Can NT-ProBNP-Guided Therapy During Hospital Admission for Acute Decompensated Heart Failure Reduce Mortality and Readmissions?). Circulation 2018;137:1671-1683.

29 Brisco MA, Zile MR, Hanberg JS, Wilson FP, Parikh CR, Coca SG, Tang WHW, Testani JM: Relevance of Changes in Serum Creatinine During a Heart Failure Trial of Decongestive Strategies: Insights From the DOSE Trial. J Card Fail 2016;22:753-760. 